\title{
Corrosion Behavior of Alloy C-276 in Supercritical Water
}

\author{
Hong Shi $\mathbb{D}^{1},{ }^{1}$ Zhigang Gao $\mathbb{D}^{1},{ }^{1}$ Zhongbiao Fan, ${ }^{1}$ Yuanyuan Ding, ${ }^{2}$ Yanxin $Q$ Qiao $\left(\mathbb{D},{ }^{3}\right.$ and \\ Zhiyuan Zhu $\mathbb{1 D}^{3}$ \\ ${ }^{1}$ College of Energy and Power Engineering, Jiangsu University of Science and Technology, Zhenjiang 212003, China \\ ${ }^{2}$ College of Aerospace Engineering, Nanjing University of Aeronautics and Astronautics, Nanjing 210016, China \\ ${ }^{3}$ School of Materials Science and Engineering, Jiangsu University of Science and Technology, Zhenjiang 212003, China
}

Correspondence should be addressed to Yanxin Qiao; yxqiao@imr.ac.cn

Received 19 June 2017; Revised 17 October 2017; Accepted 26 October 2017; Published 14 January 2018

Academic Editor: Alain Portavoce

Copyright (c) 2018 Hong Shi et al. This is an open access article distributed under the Creative Commons Attribution License, which permits unrestricted use, distribution, and reproduction in any medium, provided the original work is properly cited.

The corrosion behavior of Alloy C-276 in high-temperature and high-pressure water at $500^{\circ} \mathrm{C}$ and $25 \mathrm{MPa}$, respectively, was investigated by means of mass gain, scanning electron microscopic observation, and X-ray diffraction. The results indicated that the mass gain rate of Alloy C-276 in supercritical water obeys the parabolic law. The oxide scale was formed on Alloy C-276 with a dual-layer structure, mainly consisting of an outer Ni-rich layer and an inner $\mathrm{Cr}_{2} \mathrm{O}_{3} / \mathrm{NiCr}_{2} \mathrm{O}_{4}$ mixed layer. Tiny microcracks can also be found in the oxide scale if exposed for longer time. Meanwhile, higher temperature promotes oxide rate and results in thermal stress in the oxide film.

\section{Introduction}

The supercritical water coolant reactor (SCWR) system is a kind of Generation IV reactor program, attracting more and more attention in recent years for its high thermal efficiency and simple structure. Figure 1 shows the schematic of the SCWR. The corrosion properties of the structure material used in SCWR with thin wall exposed to supercritical water limited its popularization and application [1]. Owing to the superior mechanical properties and corrosion performance in high temperature, nickel-base alloys seemed to be the suitable materials used in SCWR [2-4]. Thus, essentially, nickel-base alloys are in high content in $\mathrm{Ni}, \mathrm{Cr}$, which could increase the oxidation and corrosion resistance of the nickel-base alloys at high temperatures [5-15]. Up to now, the corrosion behaviors of nickel-base alloys in the supercritical water have been intensely investigated in literature $[3,4,16-18]$.

As a kind of nickel-base alloys, Alloy C-276 has high mechanical strength and superior toughness in high temperature [19-22]. Besides, it is observed to have an excellent high-temperature corrosion resistance. The aim of the present work is to evaluate the corrosion behavior and corrosion mechanism of Alloy C-276 in superficial water $(\mathrm{SCW})$ at $500^{\circ} \mathrm{C}$ and at a pressure of $25 \mathrm{MPa}$.

\section{Experimental}

The Alloy C-276 used in the present study is supplied by Haynes International Corporation. The chemical composition (in wt.\%) of the C-276 is C 0.001, Si 0.03, Cr 15.88, Mn 0.5, Mo 15.64, W 3.38, Nb 0.24, Co 1.51, V 0.02, and Ni balance [15]. The C-276 plate was cut into samples with dimensions of $30 \times 20 \times 3 \mathrm{~mm}$. Then, the sample was mechanically polished to 1000\# SiC emery paper, and then, the samples were washed by ultrasound with acetone. After completion of each exposure period, the samples were taken out for oxide scale characterization. An XS105DU electric balance with an accuracy of $0.1 \mathrm{mg}$ was used to measure the weight change in each sample. The experiment was conducted in batch autoclave. Corrosion tests were conducted at $500^{\circ} \mathrm{C}$, under a pressure of $25 \mathrm{MPa}$ for time periods up to $500 \mathrm{~h}$. The observing time is $50 \mathrm{~h}, 250 \mathrm{~h}$, and $500 \mathrm{~h}$. In order to ensure the reliability of the results, 5 parallel experiment analyses are carried out.

A JSM-6480 scanning electron microscope (SEM) was used to observe the oxide scale morphology. The surfaces of the samples were plated with a thin layer of Ni coating to avoid spoliation during sample preparation. The electroless nickel bath was composed of $30 \mathrm{~g} / \mathrm{L}$ $\mathrm{NiSiO}_{4} \cdot 6 \mathrm{H}_{2} \mathrm{O}+20 \mathrm{~g} / \mathrm{L} \mathrm{NaH}_{2} \mathrm{PO}_{2} \cdot \mathrm{H}_{2} \mathrm{O}+10 \mathrm{~g} / \mathrm{L} \mathrm{NaC}_{6} \mathrm{H}_{5} \mathrm{O}_{7} \cdot 2 \mathrm{H}_{2} \mathrm{O}+$ 


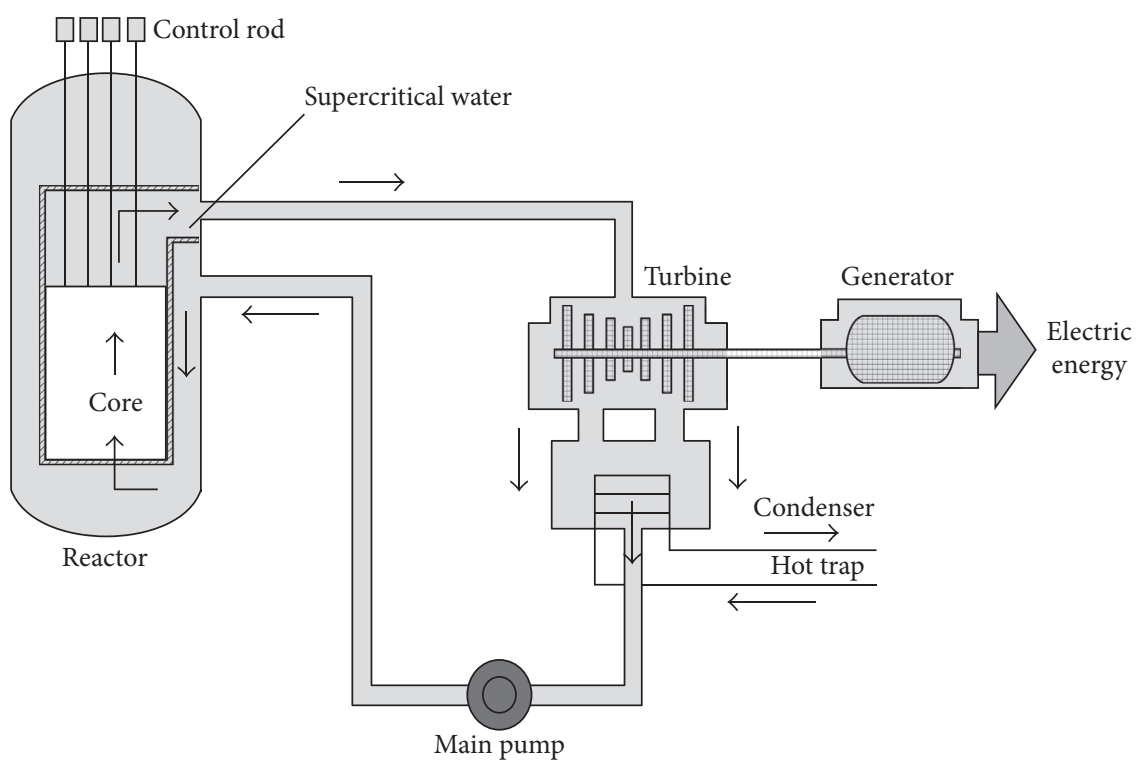

Figure 1: The schematic of the supercritical water coolant reactor.

$20 \mathrm{~g} / \mathrm{L} \mathrm{NaC}_{2} \mathrm{H}_{3} \mathrm{O}_{2} \cdot 3 \mathrm{H}_{2} \mathrm{O}$. The $\mathrm{pH}$ value is adjusted to 4.5 by $\mathrm{H}_{2} \mathrm{SO}_{4}$ at $80^{\circ} \mathrm{C}$. Oxide film sample was treated by sensitize solution $\left(10 \mathrm{~g} / \mathrm{L} \mathrm{SnCl}_{2}+1 \mathrm{ml} / \mathrm{L} 37 \% \mathrm{HCl}\right)$ and activation solution $\left(0.3 \mathrm{~g} / \mathrm{L} \mathrm{PdCl}_{2}\right)$. Samples were mounted onto epoxy resin and polished down to $0.5 \mu \mathrm{m}$ before metallurgical examination. Oxide phases were identified by an X-ray diffraction (XRD) with a $\mathrm{Cu}-\mathrm{Ka}$ radiation from Shimadzu Corporation with a wavelength of $1.5 \AA$ at $40 \mathrm{kV}$ and $30 \mathrm{~mA}$ in the 2 -theta range $20-90^{\circ}$ with a scan rate of $0.1^{\circ}$ per second.

\section{Results}

3.1. Corrosion Dynamics Curve. The variation of the weight gain for Alloy C-276 exposed to SCW at $500^{\circ} \mathrm{C}$ under a pressure of $25 \mathrm{MPa}$ with time is plotted in Figure 2. It can be analyzed with (1):

$$
\begin{aligned}
\Delta W & =k t^{n}, \\
k & =k_{0} \exp \left(-\frac{Q}{R T}\right),
\end{aligned}
$$

where $\Delta W\left(\mathrm{mg} \cdot \mathrm{cm}^{-2}\right)$ is the weight gain, $k\left(\mathrm{mg} \cdot \mathrm{cm}^{-2} \cdot \mathrm{h}^{-1}\right)$ is the rate constant, $t(\mathrm{~h})$ is the exposed time, $k_{0}\left(\mathrm{mg} \cdot \mathrm{cm}^{-2} \cdot \mathrm{h}^{-1}\right)$ is the Arrhenius constant, $Q\left(\mathrm{~J} \cdot \mathrm{mol}^{-1}\right)$ is the activation energy for oxide, $R\left(\mathrm{~J} \cdot \mathrm{mol}^{-1} \cdot \mathrm{K}^{-1}\right)$ is the gas constant, and $T(\mathrm{~K})$ is the absolute temperature.

Through data fitting, the parameter $n$ is about 0.57, which indicates that the kinetic curves of C-276 in $500^{\circ} \mathrm{C} / 25 \mathrm{MPa}$ SCW obey the parabolic law. According to the theory of high-temperature corrosion, the corrosion rate will decrease with increasing exposed time.

3.2. Surface Topography Analyses. Figure 3 shows the SEM morphology of Alloy C-276 exposed to SCW at $500^{\circ} \mathrm{C}$ for different exposure periods. After $50 \mathrm{~h}$, a thick layer of oxide film can be observed on the surface. The granular oxide

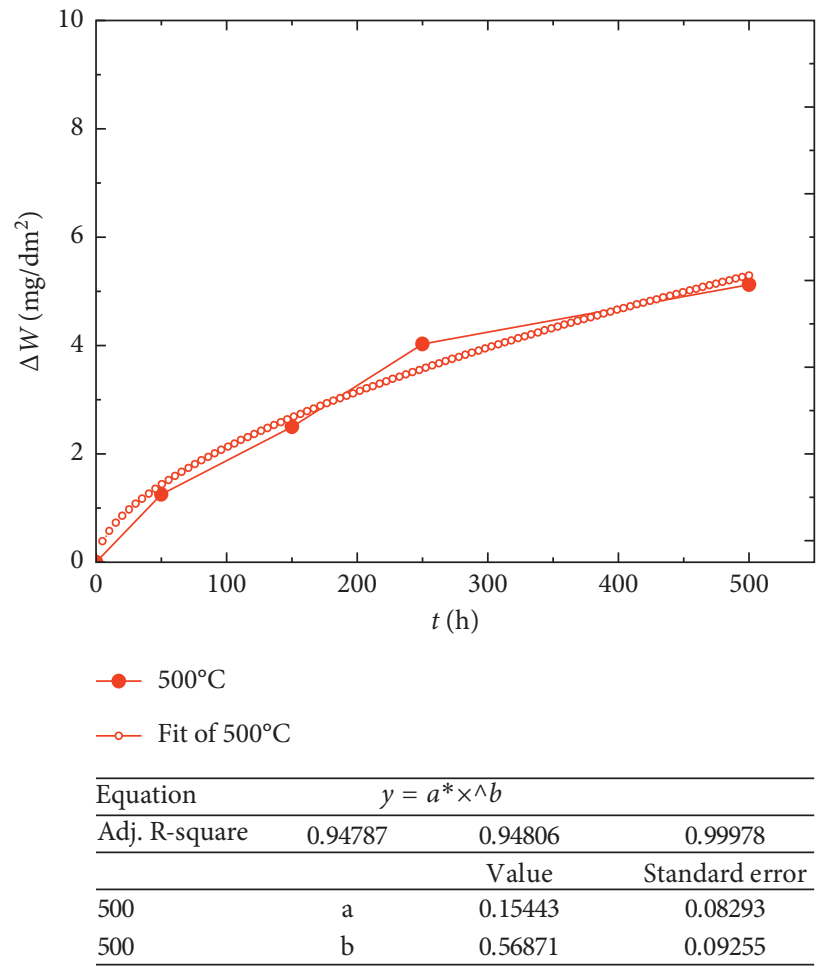

FIGURE 2: Weight gain as a function of time for C-276 exposed to SCW.

particles can also be observed dispersed on the surface of Alloy C-276, as shown in Figure 3(a). The amount and volume of oxide particles increase with the increase of exposed periods, as shown in Figure 3(b). And after 500 h, tiny cracks appear on the surface of the oxide film, as shown in Figure 3(c). The results reported by Yin [23] also found the same phenomena of tiny microcracks on the surface of the oxide film on Alloy C-276 exposed to SCW. The composition of oxide film and oxide particles after $500 \mathrm{~h}$ is analyzed by EDS. 


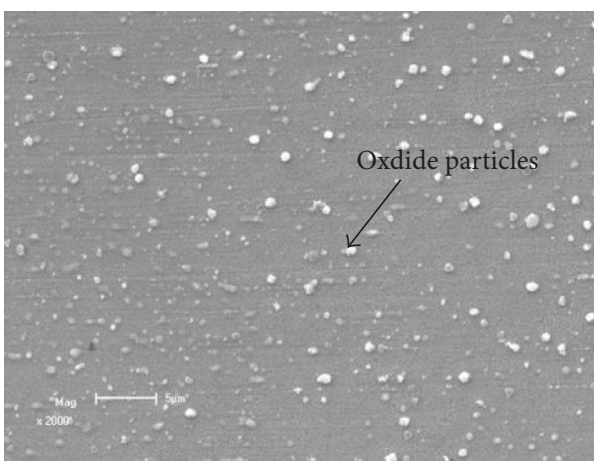

(a)

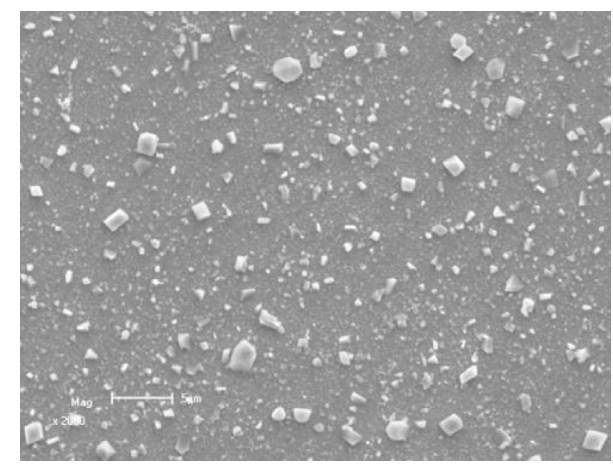

(b)

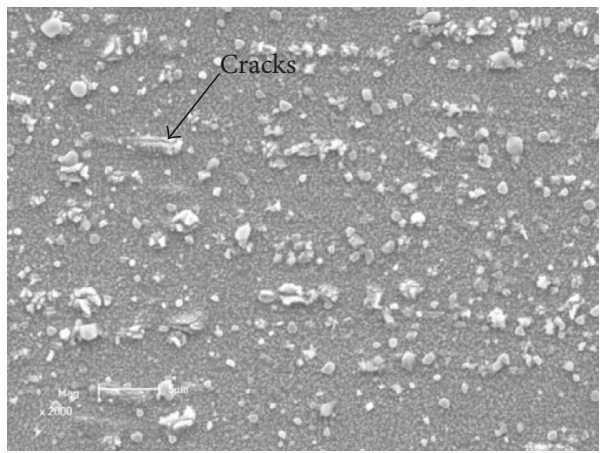

(c)

Figure 3: SEM morphologies of the oxide film formed on Alloy C-276 exposed to SCW for (a) $50 \mathrm{~h}$, (b) $250 \mathrm{~h}$, and (c) $500 \mathrm{~h}$.

3.3. EDS Analysis Corrosion Products. Figure 4 shows the EDS spectrum of the oxide film formed in SCW at $500^{\circ} \mathrm{C}$ for different exposure periods. As shown in Figure 4, the oxide film formed on the surface of Alloy C-276 is mainly composed of $\mathrm{Ni}, \mathrm{Fe}, \mathrm{Cr}, \mathrm{Mo}$, and $\mathrm{O}$. Composition of the oxide film remains constant with the increase of immersion time. The element content of the oxide film after immersion for $500 \mathrm{~h}$ is shown in Table 1 . The chemical state and composition of the oxide film should be evaluated by EDS analyses associated with XRD analyses according to the EDS spectrum normally including the base information.

3.4. XRD Analysis of the Oxide Film. The phase composition of the oxide film formed on the sample exposed to SCW at $500^{\circ} \mathrm{C}$ and $25 \mathrm{MPa}$ for $500 \mathrm{~h}$ was determined by X-ray diffraction (XRD). The XRD profile of C-276 exposed to SCW for $500 \mathrm{~h}$ is shown in Figure 5. From Figure 5, it can be deduced that the oxide film is mainly composed of $\mathrm{NiO}$, $\mathrm{Cr}_{2} \mathrm{O}_{3}, \mathrm{NiCr}_{2} \mathrm{O}_{4}$, and $\mathrm{MoO}_{2}$. However, the diffraction intensity peaks of $\mathrm{MoO}_{2}$ are significantly reduced, indicating the low content of which existed in the oxide film. $(\mathrm{Ni}, \mathrm{Mo})$ is the base of Alloy C-276. The formation of $\mathrm{Cr}_{2} \mathrm{O}_{3}$ in the oxide film can prevent the ion transport and effectively reduce the oxide reaction, thus decreasing the growth rate of the oxide film. The diffusion coefficient of metal ions in spinel $\mathrm{NiCr}_{2} \mathrm{O}_{4}$ is obviously smaller than that in its own oxide, and the existence of $\mathrm{NiCr}_{2} \mathrm{O}_{4}$ is also helpful to improve the corrosion resistance of the alloy.

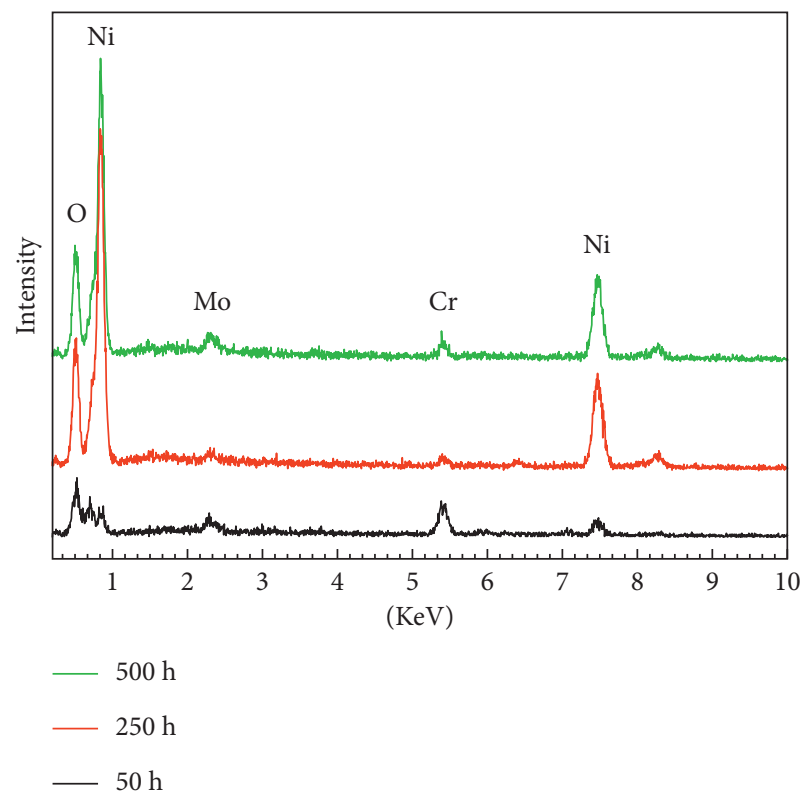

FIGURE 4: EDS spectrum of oxide scales grown on C-276 in SCW for different periods.

3.5. Cross-Sectional Morphology and Composition Analysis of Oxide Film. Figure 6 shows the cross section of the oxide film of Alloy C-276 exposed toSCW for $500 \mathrm{~h}$. As can be seen from Figure 6, the oxide film is a dual-layer structure, and 
TABLE 1: EDS of oxide particles and oxide films after immersion for $500 \mathrm{~h}$.

\begin{tabular}{lcc}
\hline Element & Oxide particle & Oxide film \\
\hline $\mathrm{O}$ & 27.51 & 25.77 \\
$\mathrm{Cr}$ & 17.69 & 23.91 \\
$\mathrm{Nb}$ & 1.51 & 2.08 \\
$\mathrm{Ni}$ & 51.73 & 46.27 \\
$\mathrm{Mo}$ & 1.56 & 1.97 \\
\hline
\end{tabular}

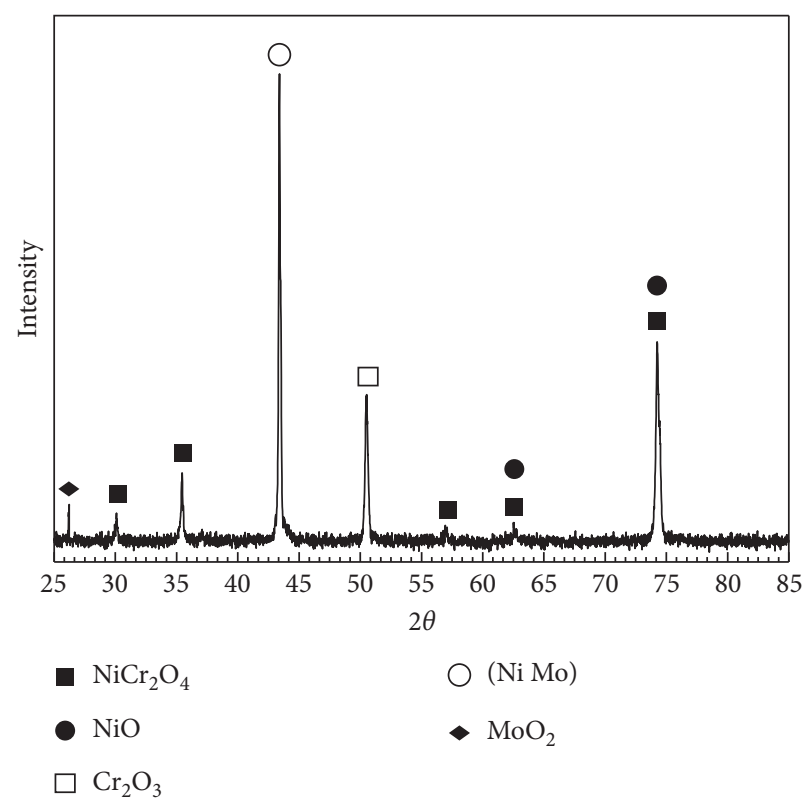

FIGURE 5: XRD profiles of C-276 exposed to SCW for $500 \mathrm{~h}$.

there is no crack between the two layers: the inner and outer oxide films. The thickness of the outer layer is slightly thicker than that of the inner layer. Table 2 presents the chemical compositions of the oxide film obtained from EDS. The outer layer of the oxide film is mainly Ni rich, and the inner layer is mainly $\mathrm{Cr}$ rich. According to the XRD results in Figure 6, the outer layer is mainly composed of $\mathrm{NiO}$ and $\mathrm{Cr}_{2} \mathrm{O}_{3}$, and the inner layer is mainly composed of $\mathrm{Cr}_{2} \mathrm{O}_{3}$ and $\mathrm{NiCr}_{2} \mathrm{O}_{4}$.

\section{Discussion}

4.1. The Growth Mechanism of the Oxide Film. The corrosion resistance of the alloy is mainly related to the properties of the oxide film formed on its surface. In the early stage of tests, the corrosion rate of Alloy C-276 is fast, and $\mathrm{Ni}$ and $\mathrm{Cr}$ can be oxidized at the same time forming $\mathrm{NiO}$ and $\mathrm{Cr}_{2} \mathrm{O}_{3}[25,26]$. When the oxide film is formed, the oxygen partial pressure at the interface of the oxide film and the matrix will be reduced leading to the decomposition of $\mathrm{NiO}$. At the same time, the diffusion coefficient of $\mathrm{Ni}$ is greater than that of $\mathrm{Cr}$; with the increasing exposed time, a double-layered oxide film is formed in the end consisting of an outer $\mathrm{NiO}$ layer and an inner $\mathrm{Cr}_{2} \mathrm{O}_{3}$ layer. On the surface, part of $\mathrm{NiO}$ and $\mathrm{Cr}_{2} \mathrm{O}_{3}$ undergoes solid-state reaction, producing the oxide $\mathrm{NiCr}_{2} \mathrm{O}_{4}$ with spinel structure. The reaction is presented as follows:

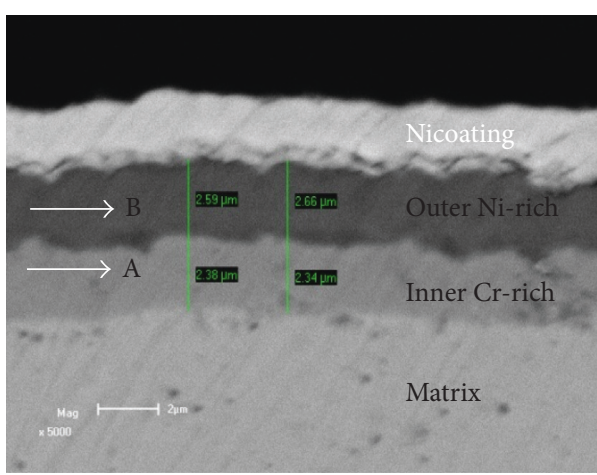

FIGURE 6: Back-scattered electron image of the cross section of the oxide film formed on C-276 in SCW for $500 \mathrm{~h}$.

Table 2: Chemical compositions of the inner oxide layer and the outer layer after immersion for $500 \mathrm{~h}$.

\begin{tabular}{lcccc}
\hline Element & $\mathrm{Ni}$ & $\mathrm{Mo}$ & $\mathrm{Cr}$ & $\mathrm{O}$ \\
\hline$A$ & 45.02 & 1.01 & 34.55 & 19.42 \\
$B$ & 51.88 & 1.21 & 25.94 & 20.97 \\
\hline & & & \\
& $\mathrm{Ni} \rightarrow \mathrm{Ni}^{2+}+2 e^{-}$ & \\
& $\mathrm{Ni}^{2+}+\frac{1}{2} \mathrm{O}_{2}+2 e^{-} \rightarrow \mathrm{NiO}$ & \\
& $\mathrm{NiO}+\mathrm{Cr}_{2} \mathrm{O}_{3} \rightarrow \mathrm{NiCr}_{2} \mathrm{O}_{4}$ &
\end{tabular}

Meanwhile, the corrosion mainly depends on the growth process of $\mathrm{Cr}_{2} \mathrm{O}_{3}$ and $\mathrm{NiCr}_{2} \mathrm{O}_{4}$; that is, the growth rate of the oxide film is determined by the rate of diffusion of the metal ions toward the outer and $\mathrm{O}^{2-}$ into the interior of the oxide film. The existence of $\mathrm{Cr}_{2} \mathrm{O}_{3}$ oxide and $\mathrm{NiCr}_{2} \mathrm{O}_{4}$ effectively inhibits the diffusion of metal ions and $\mathrm{O}^{2-}$, thereby reducing the oxide rate of the alloy.

4.2. Cracking Mechanism of the Oxide Film. The existence of stress in the oxide film is one of the decisive factors dominating the cracking of the oxide film. The stress in the oxide film can be divided into two kinds: one is the growth stress and the other is the thermal stress. For the former, its main influencing factor is the volume ratio of the oxide scale (Pilling-Bedworth ratio, PBR). The strain within the oxide film caused by PBR is given as

$$
\varepsilon=\omega\left(1-\phi^{1 / 3}\right)
$$

where $\omega$ is the proportional coefficient related to the nature of the oxide film and $\phi$ is the PBR of the oxide film. The currently relevant literature reveals that $\mathrm{Ni}$ is oxidized to $\mathrm{NiO}$ so that the volume expands to 1.65 times of the original volume, and $\mathrm{Cr}$ is oxidized to $\mathrm{Cr}_{2} \mathrm{O}_{3}$ so that the volume expands to 2.07 times of the original volume [24, 27]. Therefore, a high internal stress exists in the oxide film formation process. When the internal stress in the oxide film 
exceeds its strength, it will result in cracking of the oxide film or cracking between the layers of the oxide film [28, 29], which can even lead to the peeling of the oxide film.

The latter stress is the thermal stress. C-276 has a high thermal sensitivity to high temperature during the process of heating and cooling. The fundamental cause of the crack is that the linear expansion coefficient of the metal and oxide films is different. The thermal stresses in the metal and oxide films can be expressed as

$$
\begin{gathered}
\sigma_{\mathrm{ox}}=\frac{\int_{T_{0}}^{T} E_{\mathrm{ox}}(T)\left(\alpha_{\mathrm{m}}(T)-\alpha_{\mathrm{ox}}(T)\right) d T}{1+2(\xi / H) \int_{T_{0}}^{T}\left(E_{\mathrm{ox}}(T) / E_{\mathrm{m}}(T)\right) d T} \times \frac{1}{1-\mu_{\mathrm{ox}}}, \\
\sigma_{\mathrm{m}}=-\frac{\int_{T_{0}}^{T} E_{\mathrm{m}}(T)\left(\alpha_{\mathrm{m}}(T)-\alpha_{\mathrm{ox}}(T)\right) d T}{1+2(\xi / H) \int_{T_{0}}^{T}\left(E_{\mathrm{m}}(T) / E_{\mathrm{ox}}(T)\right) d T} \times \frac{1}{1-\mu_{\mathrm{m}}},
\end{gathered}
$$

where $\sigma_{\mathrm{ox}}$ and $\sigma_{\mathrm{m}}$ are the thermal stresses of the oxide film and the metal, respectively; $E_{\mathrm{ox}}$ and $E_{\mathrm{m}}$ are Young's moduli of the oxide film and the metal, respectively; $\alpha_{\text {ox }}$ and $\alpha_{\mathrm{m}}$ are the coefficients of linear expansion of the oxide film and the metal, respectively; $\mu_{\mathrm{ox}}$ and $\mu_{\mathrm{m}}$ are Poisson's ratios of the oxide film and the metal, respectively; $\xi$ is the thickness of the oxide film; and $H$ is the thickness of the sample.

Since the most linear expansion coefficient of the oxide film is less than that of the metal, $\alpha_{\mathrm{m}}-\alpha_{\mathrm{ox}}>0$. Meanwhile, $\alpha_{\mathrm{m}}-\alpha_{\mathrm{ox}}$ is increasing in the sample cooling process. $\Delta T<0$, so there existed compressive stress in the oxide film, and the metal has a balanced tension. $\sigma_{\mathrm{ox}}$ is proportional to $\Delta T$, so the greater the temperature difference, the greater the thermal stress. Besides, as mentioned in Section 3.1, the growth rate of $\mathrm{NiO}$ is relatively fast, and the $\mathrm{Cr}_{2} \mathrm{O}_{3}$ is covered gradually. Then, part of $\mathrm{NiO}$ and $\mathrm{Cr}_{2} \mathrm{O}_{3}$ undergo solid-state reaction, producing the oxide $\mathrm{NiCr}_{2} \mathrm{O}_{4}$ with spinel structure in the oxide process. Because the Young modulus of $\mathrm{Cr}_{2} \mathrm{O}_{3}$ and $\mathrm{NiCr}_{2} \mathrm{O}_{4}$ is much greater than that of $\mathrm{NiO}$, the thermal stress is increasing with the increase of tested periods.

The current evidence shows that the possibility of cracking of the oxide film at a constant temperature is much smaller than that in the cooling process and that the effect of temperature difference on material stress is much greater than other factors. Therefore, in real practice, we should pay attention to the turn-on and turn-off operations because of its large temperature difference.

When $\mathrm{C}-276$ is exposed to SCW, $\mathrm{Cr}$ and $\mathrm{Ni}$ are oxidized to $\mathrm{NiO}, \mathrm{Cr}_{2} \mathrm{O}_{3}$, and $\mathrm{NiCr}_{2} \mathrm{O}_{4}$, so the oxide film has a large internal stress. Meanwhile, the effect of the larger thermal stress during the sampling cooling process will also affect the oxide film to crack. Finally, the oxide film may form holes, and the oxide film can be cracked under the combined action of the above factors.

\section{Conclusions}

(1) The oxide kinetic curves of Alloy C-276 in supercritical water at $500^{\circ} \mathrm{C} / 25 \mathrm{MPa}$ obey the parabolic law.
(2) The oxide film is composed of a dual-layer structure, mainly consisting of an outer $\mathrm{NiO}$ layer and an inner $\mathrm{Cr}_{2} \mathrm{O}_{3} / \mathrm{NiCr}_{2} \mathrm{O}_{4}$ mixed layer.

(3) The growth stress and thermal stress can be responsible for spoliation of the oxide film.

\section{Conflicts of Interest}

The authors declare that they have no conflicts of interests.

\section{Acknowledgments}

This work was financially supported by National Natural Science Foundation of China (nos. 51401092, 51304041, 51434004, and U1435205), Fundamental Research Funds for the Central Universities (Grant no. N150204007), Science and Technology Program of Jiangsu Province (nos. BE2015144 and BE2015145) and Natural Science Foundation of Jiangsu Province (no. BK2011317).

\section{References}

[1] G. Wranglen, An Introduction to Corrosion and Protection of Metals, Chapman and Hall, London, UK, 1985.

[2] C. Jones, "Materials review," SLD Experience, vol. 1, p. 35, 2013.

[3] M. G. Fontana and R. W. Staehle, Advances in Corrosion Science and Technology, Plenum Press, New York, NY, USA, 1970.

[4] M. Sun, X. Wu, Z. Zhang, and E.-H. Han, "Analyses of oxide films grown on Alloy 625 in oxidizing supercritical water," Journal of Supercritical Fluids, vol. 47, no. 2, pp. 309-317, 2008.

[5] L. U. Jianshu, B. Wang, J. Zhang, and Z. Mao, "The corrosion of stainless steels in supercritical water oxide system for destroying n-amine phenol and sodium dodecyl sulphonate," Materials Science \& Engineering, vol. 22, no. 2, p. 187, 2001.

[6] A. Machet, A. Galtayries, S. Zanna et al., "XPS and STM study of the growth and structure of passive films in high temperature water on a nickel-base alloy," Electrochimica Acta, vol. 49, no. 22-23, pp. 3957-3964, 2004.

[7] A. Machet, A. Galtayries, P. Marcus, P. Combrade, P. Jolivet, and P. Scott, "XPS study of oxides formed on nickel-base alloys in high-temperature and high-pressure water," Surface \& Interface Analysis, vol. 34, no. 1, pp. 197-200, 2002.

[8] F. Di Gabriele, F. H. Stott, and Z. Liu, "Effect of experimental conditions on the metal dusting phenomenon in several commercial nickel-base alloys," Materials \& Corrosion, vol. 58, no. 2, pp. 81-86, 2015.

[9] F. Yang, X. He, L. Zhao, and X. Fang, "Influence of nickelbased alloys' mechanical properties on mechanochemical effect at crack tip in high temperature water environments," Rare Metal Materials \& Engineering, vol. 45, no. 7, pp. 1641-1646, 2016.

[10] D. Noël, O. D. Bouvier, F. Vaillant, F. Foct, and T. Magnin, "Study of the mechanisms of stress corrosion cracking of alloys 600 and 690 in primary water reactor conditions," in Proceedings of the Corrosion Deformation Interactions Conference (CDI'96), Nice, France, Sepember 1996.

[11] T. Takumi, T. Nobuo, Y. Takuyo et al., "Influence of dissolved hydrogen on structure of oxide film on alloy 600 formed in primary water of pressurized water reactors," Journal of Nuclear Science and Technology, vol. 40, no. 7, pp. 509-516, 2003. 
[12] N. Otsuka and H. Fujikawa, "Scaling of austenitic stainless steels and nickel-base alloys in high-temperature steam at 973 K," Corrosion, vol. 47, no. 4, pp. 240-248, 1991.

[13] N. Eliaz, G. Shemesh, and R. M. Latanision, "Hot corrosion in gas turbine components," Engineering Failure Analysis, vol. 9, no. 1, pp. 31-43, 2002.

[14] M. F. Montemor, M. G. S. Ferreira, N. E. Hakiki, and M. D. C. Belo, "Chemical composition and electronic structure of the oxide films formed on 3161 stainless steel and nickel based alloys in high temperature aqueous environments," Corrosion Science, vol. 42, no. 9, pp. 1635-1650, 2000.

[15] Q. Zhang, R. Tang, L. I. Cong, X. Luo, C. Long, and K. Yin, "Corrosion behavior of Ni-base alloys in supercritical water," Nuclear Engineering \& Technology, vol. 41, no. 1, pp. 107-112, 2009.

[16] X. Lu, S. Tian, T. Chen, C. Guo, G. Li, and S. L. University, "Internal oxide and internal sulfuration of Ni-base alloy with high Cr content during hot corrosion in molten sulfate," Rare Metal Materials \& Engineering, vol. 43, no. 1, p. 79, 2014.

[17] X. He, X. Xue, T. Wei, L. Zhao, and X. Gong, "Analysis on mechanical property of oxide film in stress corrosion cracking tip of nickel-based alloys," Rare Metal Materials \& Engineering, vol. 40, no. 7, pp. 1188-1191, 2011.

[18] M. Sun, X. Wu, Z. Zhang, and E. H. Han, "Analyses of oxide films grown on alloy 625 in oxidizing supercritical water," Journal of Supercritical Fluids, vol. 47, no. 2, pp. 309-317, 2008.

[19] V. Shankar, K. B. S. Rao, and S. L. Mannan, "Microstructure and mechanical properties of inconel 625 superalloy," Journal of Nuclear Materials, vol. 288, no. 2-3, pp. 222-232, 2001.

[20] K. H. Chang, J. H. Huang, C. B. Yan, T. K. Yeh, F. R. Chen, and J. J. Kai, "Corrosion behavior of alloy 625 in supercritical water environments," Progress in Nuclear Energy, vol. 57, no. 5, pp. 20-31, 2012.

[21] T. Takada, H. Omura, Y. Akai, N. Hara, N. Saito, and Y. Tsuchiya, "Corrosion performance of metals for supercritical water, oxide-utilized organic waste-processing reactors," Corrosion, vol. 62, no. 5, pp. 383-394, 2006.

[22] J. Panter, B. Viguier, J. M. Cloué, M. Foucault, P. Combrade, and E. Andrieu, "Influence of oxide films on primary water stress corrosion cracking initiation of alloy 600," Journal of Nuclear Materials, vol. 348, no. 1-2, pp. 213-221, 2006.

[23] Q. Zhang, R. Tang, K. Yin, X. Luo, and L. Zhang, "Corrosion behavior of hastelloy C-276 in supercritical water," Corrosion Science, vol. 51, no. 9, pp. 2092-2097, 2009.

[24] L. Tiefan, High Temperature Oxide and Hot Corrosion of Metal, p. 32, Chemical Industry Press, Beijing, China, 2004.

[25] B. Stellwag, "The mechanism of oxide film formation on austenitic stainless steels in high temperature water," Corrosion Science, vol. 40, no. 2-3, pp. 337-370, 1998.

[26] W. Kuang, X. Wu, E. H. Han, and J. Rao, "The mechanism of oxide film formation on alloy 690 in oxygenated high temperature water," Corrosion Science, vol. 53, no. 11, pp. 38533860, 2011.

[27] L. Meishuan, High Temperature Corrosion of Metal, p. 45, Metallurgical Industry Press, Beijing, China, 2001.

[28] K. J. Yin, S. Y. Qiu, R. Tang, Q. Zhang, and L. Zhang, "Corrosion behavior of steel p92 in supercritical water," Journal of Supercritical Fluids, vol. 50, no. 3, pp. 235-239, 2010.

[29] Y. X. Qiao, F. H. Liu, A. Ren, S. L. Jiang, and Y. G. Zheng, "Erosion-corrosion behavior of high nitrogen stainless steel and commercial 321 stainless steel," Journal of Chinese Society for Corrosion \& Protection, vol. 32, no. 2, pp. 141-145, 2012. 


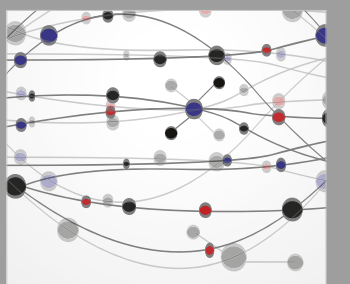

The Scientific World Journal
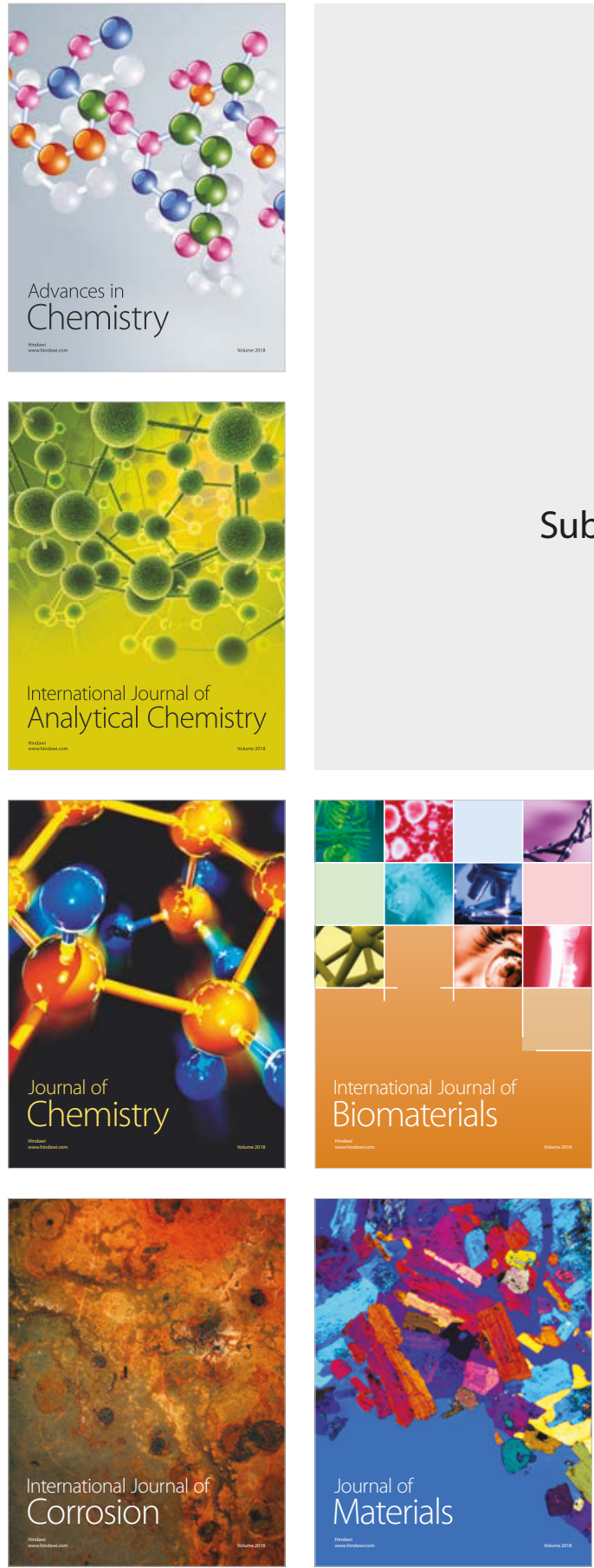

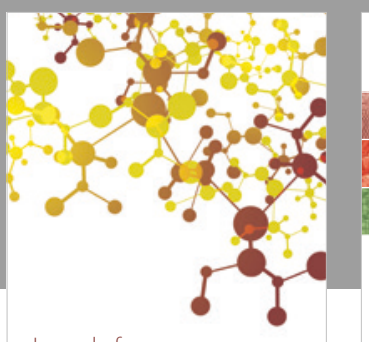

Journal of

Applied Chemistry
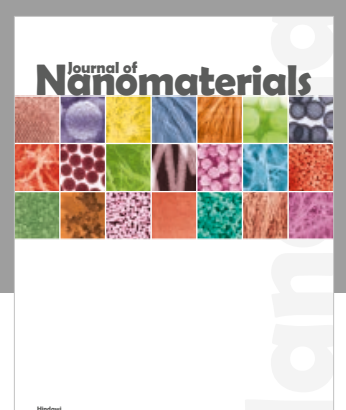

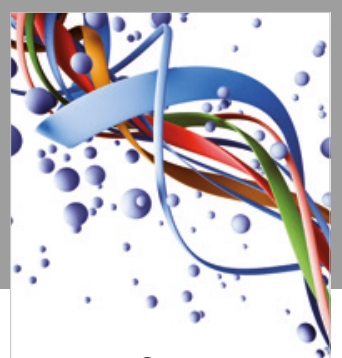

Scientifica

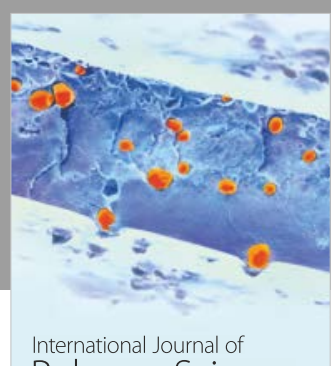

Polymer Science

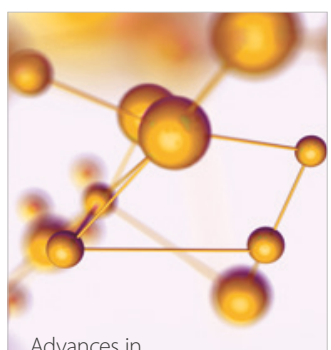

Physical Chemistry
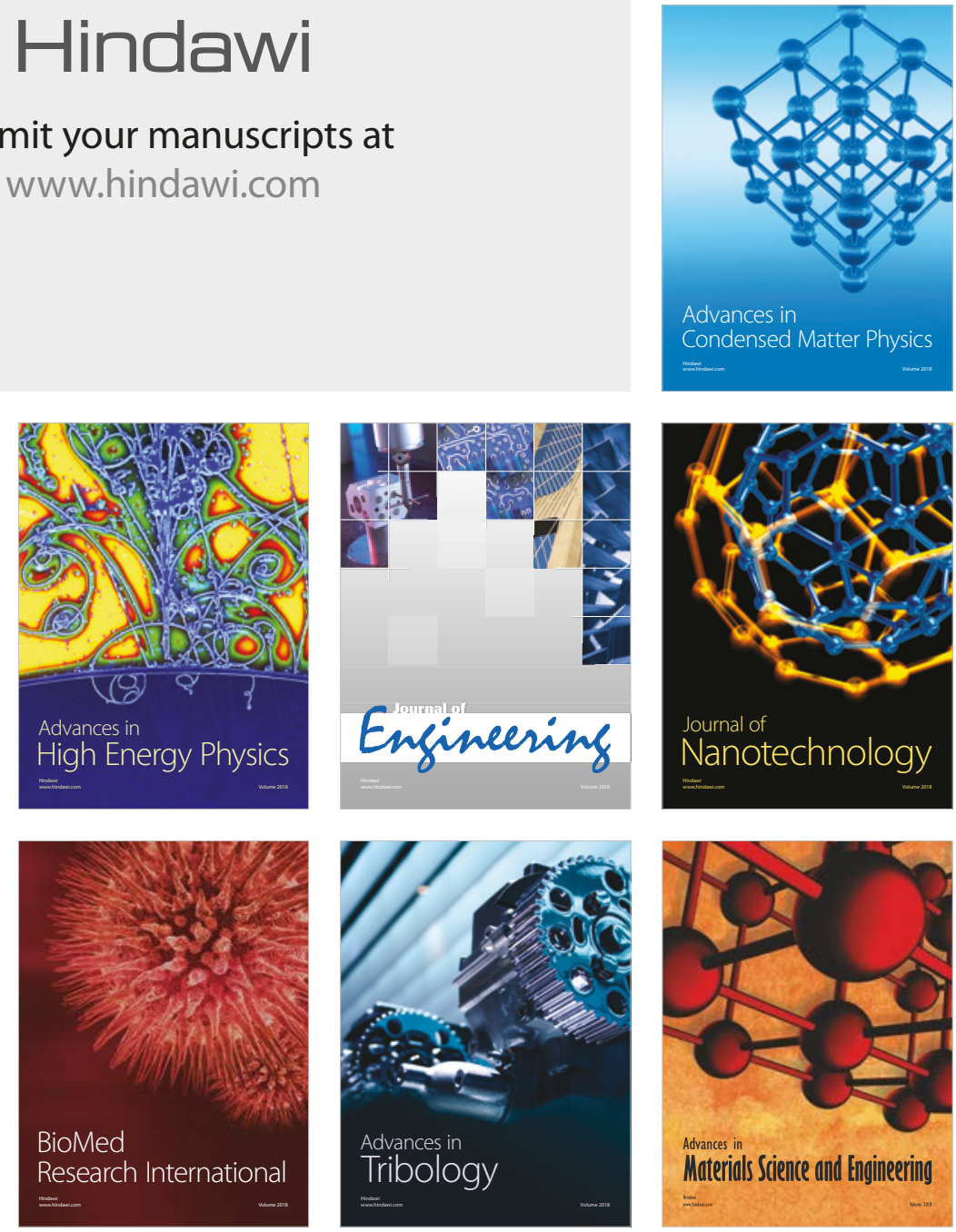